\title{
Effects of Trace Alloying Elements Fe and Cr on the Microstructure and Aging Properties of $\mathrm{Cu}-3 \mathrm{Ti}$ Alloy Foils
}

\author{
Hongliang Zhao ${ }^{1}$, Yaguang Dong ${ }^{1}$, Xianglei Dong ${ }^{1, *}$, Mingwei $\mathrm{Wu}^{2}$ and Rongping $\mathrm{Li}^{2}$ \\ 1 School of Materials Science and Engineering, Zhengzhou University, Zhengzhou 450001, China; \\ zhlwkr@zzu.edu.cn (H.Z.); dyg35360@163.com (Y.D.) \\ 2 Lingbao Jinyuan Zhaohui Copper Co., Ltd, Lingbao 472500, China; zhw8802@126.com (M.W.); \\ lirongping043@163.com (R.L.) \\ * Correspondence: dx1881112@zzu.edu.cn; Tel.: +86-371-63887502
}

Received: 10 October 2018; Accepted: 26 October 2018; Published: 29 October 2018

\begin{abstract}
In this work, the effects of an addition of trace alloying elements, $\mathrm{Fe}$ and $\mathrm{Cr}$, on the mechanical and electrical properties and corrosion resistance of $\mathrm{Cu}-3 \mathrm{Ti}$ alloy foils, have been investigated. The results showed that the individual addition of Fe leads to the formation of $\mathrm{Fe}_{2} \mathrm{Ti}$ intermetallic phase, which refines the grain size, in the solution-treated condition. With a combined addition of $\mathrm{Fe}$ and $\mathrm{Cr}$, the formation of the $(\mathrm{FeCr})_{2} \mathrm{Ti}$ phase and the precipitation of the $\beta^{\prime}-\mathrm{Cu}_{4} \mathrm{Ti}$ phase resulted in increased hardness in the peak-aged condition. The ultimate tensile strength and yield strength of the peak-aged $\mathrm{Cu}-\mathrm{Ti}-\mathrm{Fe}-\mathrm{Cr}$ alloy were $13 \%$ and $5.7 \%$ higher, than those of the $\mathrm{Cu}-3 \mathrm{Ti}$ alloy, respectively. The electrical conductivity of the peak-aged $\mathrm{Cu}-\mathrm{Ti}-\mathrm{Fe}-\mathrm{Cr}$ alloy was 3.3\% higher than that of the $\mathrm{Cu}$-Ti-Fe alloy, due to the finer $(\mathrm{FeCr})_{2}$ Ti phase and the less residual Ti atoms, in the $\mathrm{Cu}$ matrix. The combined addition of $\mathrm{Fe}$ and $\mathrm{Cr}$ elements could improve the corrosion resistance of the $\mathrm{Cu}$-Ti alloy. The $\mathrm{Cu}-\mathrm{Ti}-\mathrm{Fe}-\mathrm{Cr}$ alloy foil could obtain the best integrated properties, and the hardness, ultimate tensile strength, and electrical conductivity were $357.1 \mathrm{HV}, 1068 \mathrm{MPa}$ and $12.5 \%$ IACS, respectively.
\end{abstract}

Keywords: $\mathrm{Cu}-3 \mathrm{Ti}$ alloy foil; aging treatment; precipitation strengthening; enhanced properties

\section{Introduction}

Age-hardenable $\mathrm{Cu}$-based alloys, which have good mechanical and electrical properties, are widely used in components of various electronic devices, such as connectors, relays, and switches [1-7]. Recent rapid advances of densely-integrated and the reductions in size and thickness of electronic components have led to more severe requirements for excellent mechanical and electrical properties of the $\mathrm{Cu}$-based alloys. Among them, $\mathrm{Cu}$-Be alloys appear to be an ideal choice to exhibit superior mechanical and electrical properties, but the high-cost of raw materials and toxic effects of the Beryllium compounds restrict their applications. $\mathrm{Cu}-\mathrm{Ti}$ alloys strengthened by the formation of the ordered, metastable, and coherent $\beta^{\prime}-\mathrm{Cu}_{4} \mathrm{Ti}$ phase have comparable mechanical properties to the $\mathrm{Cu}$-Be alloys, after suitable treatment [6-10], which has been regarded to be one of the potential materials that could replace the $\mathrm{Cu}$-Be alloys.

Addition of alloying element appears to be an effective way to improve the mechanical and electrical properties of the age-hardenable $\mathrm{Cu}$-Ti alloys [11-15]. Extensive investigations have been carried out to realize the effects of various alloying elements on the age hardening behavior of the $\mathrm{Cu}$-Ti alloys. The Fe element can effectively suppress the grain coarsening of the $\mathrm{Cu}$-Ti alloys, in the solution-treated condition, which improves the mechanical properties of the $\mathrm{Cu}$-Ti alloys, due to 
formation of the Fe-Ti intermetallic phases. Markandeya et al. have reported that addition of $1 \% \mathrm{Cr}$ results in an improvement of the mechanical properties of $\mathrm{Cu}$-3Ti alloy [11].

It has been reported that both the hardness and electrical conductivity of the $\mathrm{Cu}-2 \mathrm{Fe}-0.7 \mathrm{Cr}$ alloy are higher than those of the $\mathrm{Cu}-1 \mathrm{Fe}$ alloy, after the same heat treatment [16]. It is of interest to investigate the age-hardening effect of the $\mathrm{Cu}-3 \mathrm{Ti}$ alloy by a combined addition of the $\mathrm{Fe}$ and $\mathrm{Cr}$ elements. Furthermore, the application of the $\mathrm{Cu}$-Ti alloys, in a corrosive environment, has created a strong requirement for an improved corrosion resistance and better mechanical and electrical properties [17]. In this study, the effects of trace amounts of $\mathrm{Fe}$ - and $\mathrm{Cr}$-addition on the mechanical and electrical properties and the corrosion resistance of $\mathrm{Cu}-3 \mathrm{Ti}$ alloy foils have been investigated. The precipitation kinetics of the phase transformation of the studied alloys has also been studied.

\section{Experimental Procedure}

The studied alloys were melted and cast in an induction furnace (NMS-GYI, Sichuan, China), and the nominal compositions of the studied alloys were $\mathrm{Cu}-3 \mathrm{Ti}, \mathrm{Cu}-3 \mathrm{Ti}-0.2 \mathrm{Fe}$, and $\mathrm{Cu}-3 \mathrm{Ti}-0.2 \mathrm{Fe}-0.2 \mathrm{Cr}$ (wt. \%) alloys, respectively. Raw materials were used as $99.99 \%$ electrolytic copper, $99.9 \%$ titanium, $99.99 \%$ ferrous, and $99.95 \%$ chromium. The ingots, thus obtained, were homogenized at $840{ }^{\circ} \mathrm{C}$, for $12 \mathrm{~h}$, in an Ar atmosphere. Then the plates, with a thickness of $5 \mathrm{~mm}$, after soaking, were subsequently polished to obtain flats, with a thickness of $4.5 \mathrm{~mm}$. Flats were solution-treated at $900{ }^{\circ} \mathrm{C}$, for $4 \mathrm{~h}$, in a heat-treatment furnace (SX 2-5-12, Shanghai, China), in an Ar atmosphere, immediately followed by water quenching. Then, the solution-treated plates were ground mechanically to $4 \mathrm{~mm}$, by using the emery paper, which were cold-rolled to foil $(0.1 \mathrm{~mm})$, with a reduction of $97.5 \%$. Three different samples that were cut from cold-rolled foils were aged at $450{ }^{\circ} \mathrm{C}$, for different times, respectively.

Metallographic specimens of any condition were etched in a solution of $5 \mathrm{~g} \mathrm{FeCl}_{3}, 20 \mathrm{~mL}$ $\mathrm{HCl}$, and $100 \mathrm{~mL}$ distilled water, after mechanical polishing, and then the microstructures were characterized by optical microscopy (OM; Leica DM 4000M, Wetzlar, Germany) and scanning electron microscopy (SEM; Philips Quanta 200, Amsterdam, The Netherlands). The fracture surfaces were observed, using SEM. Hardness tests were carried out on an Vickers micro-hardness tester (HXD-1000TMSC/LCD, Shanghai, China), with a load of $500 \mathrm{~g}$ and holding time of $15 \mathrm{~s}$, taking the average of seven or more indentations. Electrical conductivity was measured at $20^{\circ} \mathrm{C}$, using an electrical conductivity device (STR-B, Shanghai, China), taking the average of five values, and presented by International Annealed Copper Standard (IACS). Tensile specimens with a shape of a dog-bone, and gauge dimension of $30 \mathrm{~mm} \times 3 \mathrm{~mm} \times 0.1 \mathrm{~mm}$, were tested on the electric universal testing machine (Shimadzu AG-IC, Tokyo, Japan), at a crosshead speed of $0.5 \mathrm{~mm} / \mathrm{min}$, at room temperature. Electrochemical measurements were examined using an electrochemical workstation (RST5000, Suzhou, China), in $3.5 \mathrm{wt}$. \% NaCl solution, taken three times, for each sample, and replicating the results. After all samples were immersed in the $3.5 \mathrm{wt}$. $\% \mathrm{NaCl}$ solution, for $90 \mathrm{~min}$, the electrochemical measurements were conducted in a three-electrode cell, which consisted of a platinum counter electrode and an saturated calomel electrode (SCE) reference electrode and a working electrode.

\section{Results and Discussion}

\subsection{Microstructure of the Specimens in the Solution-Treated Condition}

Solution treatment is a significant process to obtain a supersaturated solid solution and to prepare for the later aging treatment $[17,18]$. Figure 1 shows the optical micrographs of the $\mathrm{Cu}-3 \mathrm{Ti}, \mathrm{Cu}-\mathrm{Ti}-\mathrm{Fe}$, and $\mathrm{Cu}-\mathrm{Ti}-\mathrm{Fe}-\mathrm{Cr}$ alloys, in the solution-treated condition. It can be seen that the equiaxed grains existed in the three alloys. With the addition of the $\mathrm{Fe}$ and $\mathrm{Cr}$ elements, grain size decreased gradually, from $25 \pm 5 \mu \mathrm{m}$ in the $\mathrm{Cu}-3 \mathrm{Ti}$, to $12 \pm 2 \mu \mathrm{m}$ in the $\mathrm{Cu}$-Ti-Fe-Cr alloy. As shown in Figure $1 \mathrm{~b}$, the rod-shaped and granular phases were mostly distributed in the equiaxed grains and the grain boundaries, by an individual addition of the Fe element, and these phases were the $\mathrm{Fe}_{2} \mathrm{Ti}$ intermetallic phase, as has been confirmed by Mineau et al. [18]. Measured by the Image J software, the volume fraction of the rod-shaped phase 
shown in Figure $1 \mathrm{~b}$ was about $7.8 \%$, more than $5.7 \%$ of that shown in Figure $1 \mathrm{c}$. Therefore, the combined addition of $\mathrm{Fe}$ and $\mathrm{Cr}$ elements decreased the number of rod-shaped phases, in the grain boundaries.


Figure 1. Optical micrographs of the solution-treated specimens, at $900{ }^{\circ} \mathrm{C}$, for $4 \mathrm{~h}$. (a) Cu-3Ti; (b) Cu-Ti-Fe; and (c) Cu-Ti-Fe-Cr.

The SEM image and the EDS results of the solution-treated Cu-Ti-Fe-Cr alloy are shown in Figure 2, to confirm the composition of the intermetallic phase. The intermetallic phases were distributed in the grain boundaries and the interior of grains. Most of intermetallic phases, distributed in the interior of grains, had a granular shape. Additionally, the sizes of the intermetallic phases were in the range of $1 \sim 2 \mu \mathrm{m}$. According to the EDS results, it could be seen that the Cr element had mostly dissolved into the Fe-Ti intermetallic phases, which indicated that the intermetallic phases were $(\mathrm{FeCr})_{2} \mathrm{Ti}$, belonging to the substitutional solid solution and the C14-Laves phases [19].
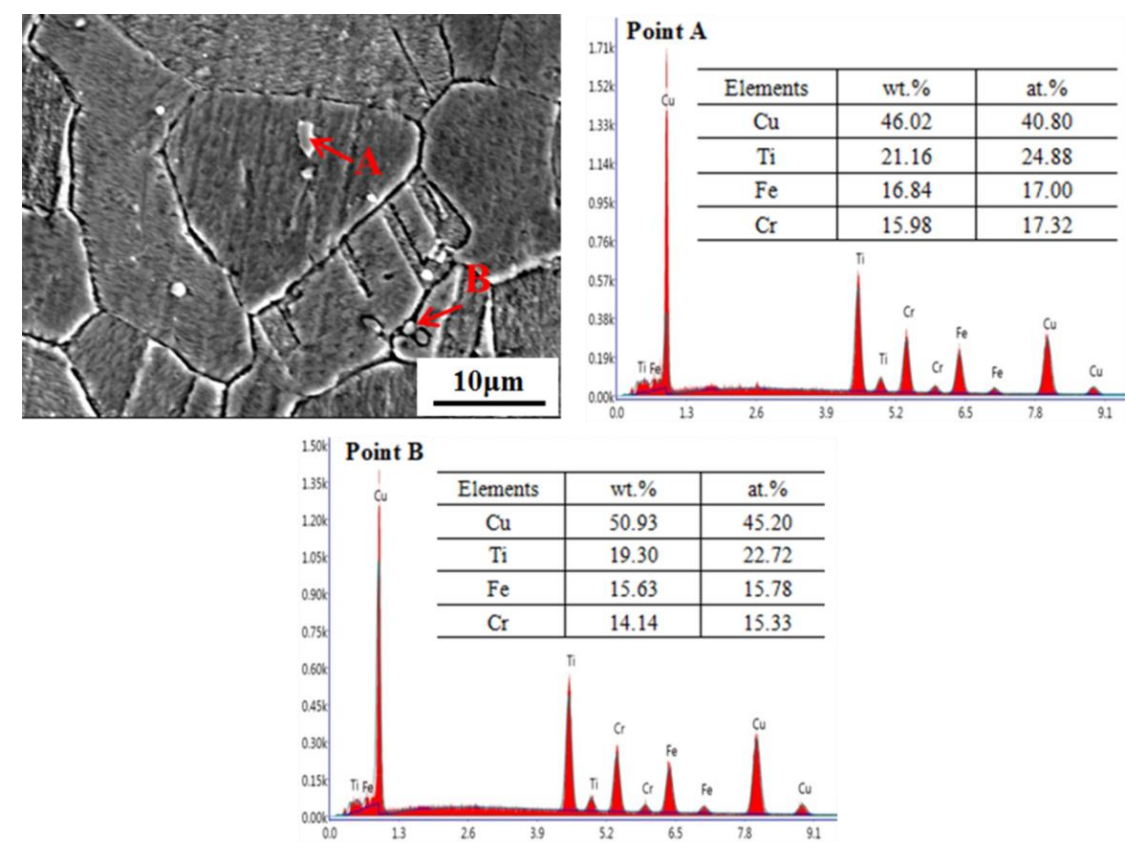

Figure 2. SEM image and the EDS results of the solution-treated $\mathrm{Cu}-\mathrm{Ti}-\mathrm{Fe}-\mathrm{Cr}$ alloy, at $900{ }^{\circ} \mathrm{C}$, for $4 \mathrm{~h}$. 


\subsection{Mechanical Properties}

The variations in hardness of the three alloys, in the different conditions, are shown in Figure 3. The mechanical properties of the alloys in the solution-treated condition had significant effects on the subsequent cold deformation [20]. Figure 3a shows the variation in hardness of the three alloys, in the solution-treated condition. When $0.2 \% \mathrm{Fe}$ was added into the $\mathrm{Cu}-3 \mathrm{Ti}$ alloy, the value of the hardness had decreased to $110.9 \pm 3.1 \mathrm{HV}$ from $124.7 \pm 3.8 \mathrm{HV}$ of the $\mathrm{Cu}-3 \mathrm{Ti}$ alloy. The hardness of the $\mathrm{Cu}$-Ti-Fe-Cr alloy was 7.1\% higher than that of the $\mathrm{Cu}$-Ti-Fe alloy, due to the stronger grain refinement strengthening caused by the finer grain size, and the stronger second phase strengthening caused by the finer $(\mathrm{FeCr})_{2} \mathrm{Ti}$ phase. The formation of the $\mathrm{Fe}_{2} \mathrm{Ti}$ and the $(\mathrm{FeCr})_{2} \mathrm{Ti}$ phases could decrease the number of Titanium atoms in the $\mathrm{Cu}$ matrix. Therefore, even though the $\mathrm{Fe}_{2} \mathrm{Ti}$ and the $(\mathrm{FeCr})_{2} \mathrm{Ti}$ phases played some part in the grain refinement and the precipitate strengthening processes, the hardness of the $\mathrm{Cu}-3 \mathrm{Ti}$ alloy was still higher than the $\mathrm{Cu}$-Ti-Fe and the $\mathrm{Cu}-\mathrm{Ti}-\mathrm{Fe}-\mathrm{Cr}$ alloys, which was consistent with that found in Reference [3], and was ascribed to the stronger solution strengthening effect of the Titanium atoms.

All solution-treated alloys were cold-rolled to $0.1 \mathrm{~mm}$, with the same reduction of $97.5 \%$, and then the aging treatments were carried out, at $450{ }^{\circ} \mathrm{C}$. Figure $3 \mathrm{~b}$ shows the influence of aging time in the hardness of the three alloys. For all three samples, the hardness rapidly increased to peak values but then moderately reduced with an increase in the aging time. It could also be observed that both the values of the peak hardness and the peak aging time increased with the addition of the $\mathrm{Fe}$ and $\mathrm{Cr}$. In the binary Cu-3Ti alloy, a peak value of $340.2 \pm 4.0 \mathrm{HV}$ was obtained at the aging time of $60 \mathrm{~min}$, whereas, the $\mathrm{Cu}-\mathrm{Ti}-\mathrm{Fe}-\mathrm{Cr}$ alloy exhibited the highest value of peak hardness, $357.1 \pm 4.6 \mathrm{HV}$, at the longest peak aging time of $100 \mathrm{~min}$.


Figure 3. Variation of Hardness of the three alloys. (a) In the solution-treated condition; (b) aging at $450{ }^{\circ} \mathrm{C}$, after the cold-rolling.

The mechanical properties of the three peak-aged alloy foils have been compared in Table 1. The ultimate tensile strength (UTS) value of the Cu-Ti-Fe alloy was $996 \pm 17 \mathrm{MPa}$, which was $5.4 \%$ higher than that of the Cu-3Ti alloy, whereas, the value of yield strength (YS) was nearly equal to the peak-aged $\mathrm{Cu}-3 \mathrm{Ti}$ alloy. Addition of the Fe element also decreased the elongation from $2.2 \%$ of the $\mathrm{Cu}-3 \mathrm{Ti}$ alloy to $1.9 \%$. The UTS and YS values of the $\mathrm{Cu}-\mathrm{Ti}-\mathrm{Fe}-\mathrm{Cr}$ alloy were significantly higher than those of the $\mathrm{Cu}-3 \mathrm{Ti}, 13 \%$ and $5.7 \%$, respectively, while the elongation of the $\mathrm{Cu}-\mathrm{Ti}-\mathrm{Fe}-\mathrm{Cr}$ alloy was similar to that of the binary $\mathrm{Cu}-3 \mathrm{Ti}$ alloy. 
Table 1. Comparison of mechanical properties of three alloy foils in the peak-aged condition.

\begin{tabular}{cccc}
\hline Mechanical properties & Cu-3Ti & Cu-Ti-Fe & Cu-Ti-Fe-Cr \\
\hline Peak hardness (HV) & $340.2 \pm 4.0$ & $347.3 \pm 5.4$ & $357.1 \pm 4.6$ \\
Ultimate tensile strength (MPa) & $945 \pm 16$ & $996 \pm 17$ & $1068 \pm 21$ \\
Yield strength (MPa) & $923 \pm 8$ & $926 \pm 6$ & $976 \pm 11$ \\
Elongation (\%) & $2.2 \pm 0.1$ & $1.9 \pm 0.1$ & $2.2 \pm 0.1$ \\
\hline
\end{tabular}

There were two stages of interpretation for the variation of mechanical properties during the aging process. In the initial period of the aging process, the fine coherent $\beta^{\prime}$-Cu $\mathrm{Cu}_{4} \mathrm{Ti}$ phase precipitated from the supersaturated $\mathrm{Cu}$ matrix. Therefore, the hardness rapidly increased to the peak value, indicating a strong coherent strengthening effect of the $\beta^{\prime}-\mathrm{Cu}_{4} \mathrm{Ti}$ phase [21]. In the mid-late period of the aging process, further aging gave rise to the transformation from coherent $\beta^{\prime}-\mathrm{Cu}_{4} \mathrm{Ti}$ phase to the incoherent $\beta-\mathrm{Cu}_{4} \mathrm{Ti}$ phase, and the coarsening of the $\beta-\mathrm{Cu}_{4} \mathrm{Ti}$ phase [22]. As the strengthening effect of the $\beta^{\prime}-\mathrm{Cu}_{4} \mathrm{Ti}$ phase was stronger than that of the $\beta-\mathrm{Cu}_{4} \mathrm{Ti}$ phase, the value of hardness reduced, moderately. The formation rate of the discontinuous $\beta-\mathrm{Cu}_{4} \mathrm{Ti}$ phase depended on the diffusion rate of the $\mathrm{Ti}$ atoms [15]. The $\mathrm{Fe}_{2} \mathrm{Ti}$ intermetallic phase suppressed the diffusion of the $\mathrm{Ti}$ atoms, resulting in the suppression of the phase transformation from the $\beta^{\prime}-\mathrm{Cu}_{4} \mathrm{Ti}$ to the $\beta-\mathrm{Cu}_{4} \mathrm{Ti}$ phase. During the cold-rolling, the high density dislocation interacted with the $\mathrm{Fe}_{2} \mathrm{Ti}$ phase, in a bypass mode, which is called the Orowan mechanism. The peak-aged hardness and the tensile strength of the $\mathrm{Cu}$-Ti-Fe alloy increased due to the addition of the Fe. The $\mathrm{Cr}$ increased the high temperature stability of the $\mathrm{Fe}_{2} \mathrm{Ti}$ phase, which resulted in the lengthened peak-aging time. The $(\mathrm{FeCr})_{2} \mathrm{Ti}$ phase, with a smaller size, showed a stronger strengthening effect caused by the Orowan mechanism, resulting in an improvement of the mechanical properties. Therefore, the synergistic effect of the $(\mathrm{FeCr})_{2} \mathrm{Ti}$ and the $\beta^{\prime}-\mathrm{Cu}_{4} \mathrm{Ti}$ phases was responsible for the most-optimized mechanical properties of the $\mathrm{Cu}-\mathrm{Ti}-\mathrm{Fe}-\mathrm{Cr}$ alloy, in the peak-aged condition.

The influence of alloying elements on the fracture mechanism of the $\mathrm{Cu}$-3Ti alloy foils was realized, and the fracture surfaces of all three alloys in the peak-aged condition, scanned by SEM, are shown in Figure 4. It reveals that the fractographies of all three alloys were composed of flat facets resembling cleavage and dimples, manifesting a mixed-rupture mode. For the $\mathrm{Cu}$-Ti-Fe alloy, the size of the $\mathrm{Fe}_{2} \mathrm{Ti}$ phase was larger than the $(\mathrm{FeCr})_{2} \mathrm{Ti}$ phase, and there was a greater number of fracture positions, due to the dislocation pile-up and tangling around the $\mathrm{Fe}_{2} \mathrm{Ti}$ phase during the tensile tests. Therefore, more flat facets and shallower dimples were found, and there were also a few river-like morphologies of the quasi-cleavage, as shown in Figure $4 \mathrm{~b}$. The more-uniform distribution and smaller size of the $(\mathrm{FeCr})_{2} \mathrm{Ti}$ phase, improved the formation of dimples. Therefore, the fracture surface of the $\mathrm{Cu}-\mathrm{Ti}-\mathrm{Fe}-\mathrm{Cr}$ alloy was dominated by dimples, whose size was close to that of the $\mathrm{Cu}-3 \mathrm{Ti}$ alloy. 

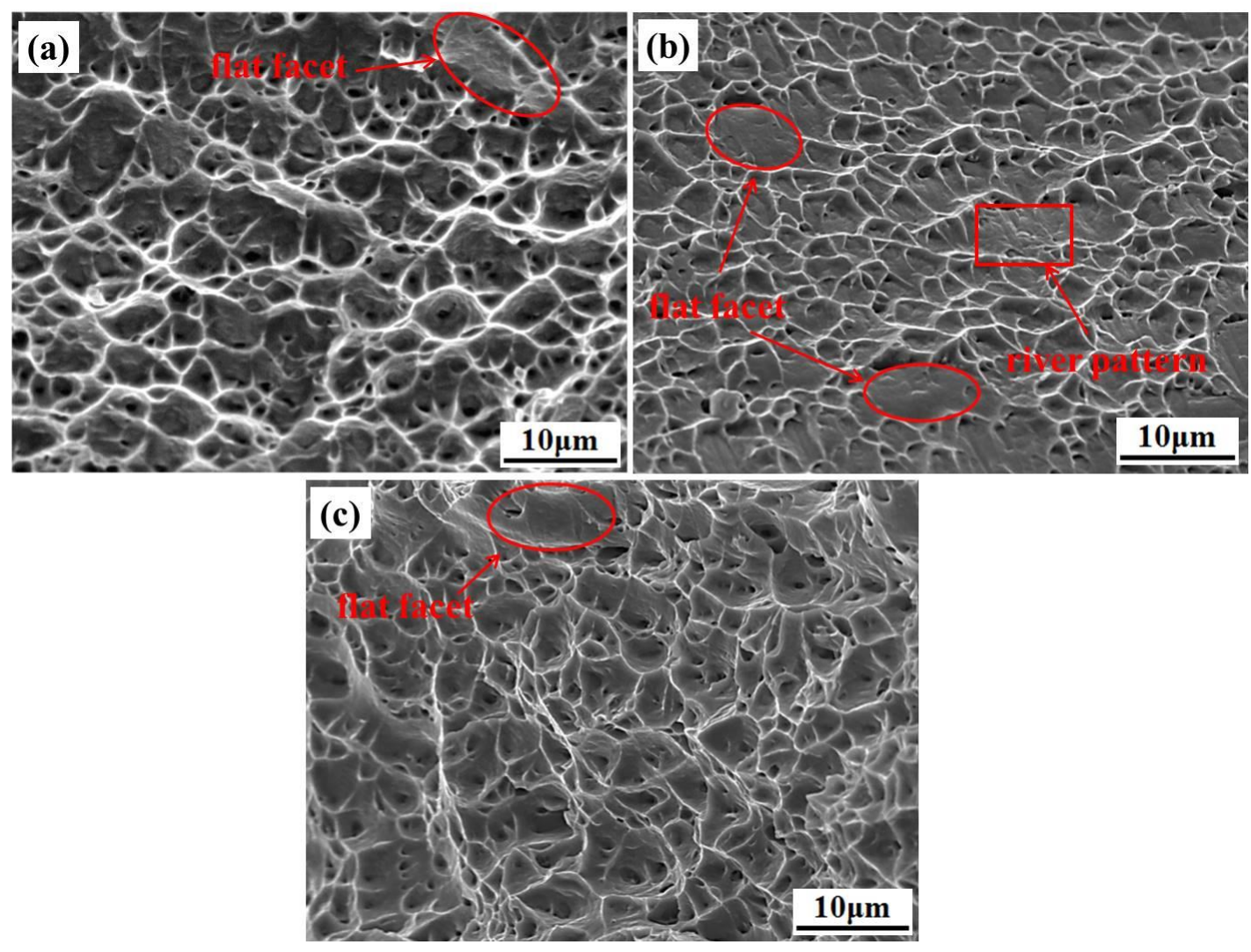

Figure 4. SEM images of the fracture surfaces of the three alloy foils in the peak-aged condition. (a) Cu-3Ti; (b) Cu-Ti-Fe; (c) Cu-Ti-Fe-Cr.

\subsection{Electrical Properties}

The solute Ti atoms, precipitated from the $\mathrm{Cu}$ matrix during aging could lead to the increment of electrical conductivity [13]. The electrical conductivities of all three alloys, in the peak-aged condition, are listed in Table 2. Individual addition of the Fe lowered the electrical conductivity of the Cu-3Ti alloy in the peak-aged condition. Additionally, the $\mathrm{Cu}-\mathrm{Ti}-\mathrm{Fe}-\mathrm{Cr}$ alloy had an electrical conductivity of $12.5 \pm 0.1 \%$ IACS, which was 3.3\% higher than that of the peak-aged Cu-Ti-Fe alloy due to the refinement of the $\mathrm{Fe}_{2} \mathrm{Ti}$ phase and the precipitation of the $\beta^{\prime}-\mathrm{Cu}_{4} \mathrm{Ti}$ phase.

Table 2. Electrical conductivities of the three alloy foils, in the peak-aged condition.

\begin{tabular}{cc}
\hline Alloys & Peak aging EC (\%IACS) \\
\hline Cu-3Ti & $13.1 \pm 0.1$ \\
Cu-Ti-Fe & $12.1 \pm 0.2$ \\
Cu-Ti-Fe-Cr & $12.5 \pm 0.1$ \\
\hline
\end{tabular}

The electrical conductivity of the copper titanium alloys mainly depends on the residual content of the solute Ti atoms, in the matrix [10]. The more phases precipitated, the purer the $\mathrm{Cu}$ matrix is, and the higher the electrical conductivity is. The precipitation kinetics of the phase transformation of the three alloys could be studied through a variation of electrical conductivity [23].

Volume fractions of the precipitates are linearly related to the electrical conductivity, as in Equation (1) [24].

$$
\sigma=\sigma_{0}+A f
$$


where $\sigma$ is electrical conductivity of the aged specimen, $\sigma_{0}$ is the electrical conductivity of the cold-rolled specimen, $A$ is the aging constant, and $f$ is the volume fraction of the precipitates. When $f=1$, $A=\sigma_{\max }-\sigma_{0}$.

With the increment of aging time, $f$ can be expressed using Avrami's empirical equation [25],

$$
f=1-\exp \left(-b t^{n}\right)
$$

where $b$ is the constant related to the phase transformation temperature and the composition of the matrix, and $n$ is the constant related to the type of phase transformation and the nucleation position.

Equation (3) can be transformed by Equation (2),

$$
\ln \left(\ln \frac{1}{1-f}\right)=\ln b+n \ln t
$$

The electrical conductivity of the $\mathrm{Cu}$-Ti-Fe-Cr alloy was obtained in range of $0 \mathrm{~min}$ to $1800 \mathrm{~min}$, and the value of $\sigma_{\max }$ was the electrical conductivity of the alloys aged at $1800 \mathrm{~min}$. The electrical conductivity and the volume fraction of the precipitates, with different aging times, are listed in Table 3. After the alloys were treated with solution process and the cold deformation, the electrical conductivity increased remarkably, during the aging process, because the high storing energy produced by the cold-rolling accelerated the precipitation process. The volume fraction of precipitates was calculated by substituting the values of $\sigma, A$, and $\sigma_{0}$, in Equation 1 . Figure 5 shows the relation between the volume fraction and the transformation time, when aging at $450{ }^{\circ} \mathrm{C}$. Figure 5 a exhibits $\ln (\ln (1 /(1-f)))$ as a function of $\ln t$. The relative parameters $b$ and $n$ were obtained by fitting the curves, according to Equation 3. According to the transformation kinetics equations calculated by the values of $b$ and $n$, the kinetic curves of the phase transformation and the corresponding Avrami-equations of the phase transformation are shown in Figure 5b. It can be seen that the transformation trend of all three alloys were similar. The transformation rates increased gradually but then decreased by an increase in the aging time. In the initial period of the aging process, the dissolution of the Fe and Cr elements, into the $\mathrm{Cu}$ matrix, led to a lower volume fraction in the $\mathrm{Cu}-\mathrm{Ti}-\mathrm{Fe}-\mathrm{Cr}$ alloy, due to the suppression of the precipitation. Both the electrical conductivity and the volume fraction of the three alloys increased with the increment of the aging time, due to the precipitation of the Ti atoms from the supersaturated solid solution. The slope change of the $f$ - $t$ curves could be related to the $n$-value, which depends on the type of phase transformation and the nucleation location. A long time later, the content of the solute $\mathrm{Ti}$ atoms decreased, and the Contrell atmospheres could be formed by the interaction between the high-density dislocation and the residual Ti atoms in the $\mathrm{Cu}$ matrix, which suppressed the precipitation of the Ti atoms [26]. As a result, the transformation rate and the electrical conductivity tended to be constant with the lengthened aging time.

Table 3. Electrical conductivities and volume fractions of the three alloy foils, with different aging times, at $450{ }^{\circ} \mathrm{C}$.

\begin{tabular}{ccccccc}
\hline \multirow{2}{*}{ t/min } & \multicolumn{2}{c}{ Cu-3Ti } & \multicolumn{2}{c}{ Cu-Ti-Fe } & \multicolumn{2}{c}{ Cu-Ti-Fe-Cr } \\
\cline { 2 - 7 } & $\sigma / \%$ IACS & $f$ & $\sigma / \%$ IACS & $f$ & $\sigma / \%$ IACS & $f$ \\
\hline 0 & $4.5 \pm 0.1$ & 0 & $4.8 \pm 0.1$ & 0 & $4.5 \pm 0.1$ & 0 \\
60 & $13.1 \pm 0.1$ & 0.3613 & $12.1 \pm 0.1$ & 0.3303 & $10.6 \pm 0.1$ & 0.2919 \\
100 & $15.0 \pm 0.1$ & 0.4412 & $14.0 \pm 0.1$ & 0.4163 & $12.5 \pm 0.1$ & 0.3828 \\
330 & $21.0 \pm 0.1$ & 0.6933 & $20.0 \pm 0.1$ & 0.6878 & $18.2 \pm 0.2$ & 0.6555 \\
600 & $22.4 \pm 0.2$ & 0.7521 & $21.7 \pm 0.1$ & 0.7647 & $20.8 \pm 0.1$ & 0.7799 \\
900 & $24.3 \pm 0.1$ & 0.8319 & $23.5 \pm 0.2$ & 0.8462 & $22.4 \pm 0.1$ & 0.8565 \\
1200 & $25.3 \pm 0.1$ & 0.8740 & $24.9 \pm 0.1$ & 0.9095 & $23.7 \pm 0.1$ & 0.9187 \\
1500 & $27.4 \pm 0.1$ & 0.9622 & $26.0 \pm 0.2$ & 0.9593 & $24.6 \pm 0.2$ & 0.9617 \\
1800 & $28.3 \pm 0.1$ & 1 & $26.9 \pm 0.2$ & 1 & $25.4 \pm 0.1$ & 1 \\
\hline
\end{tabular}



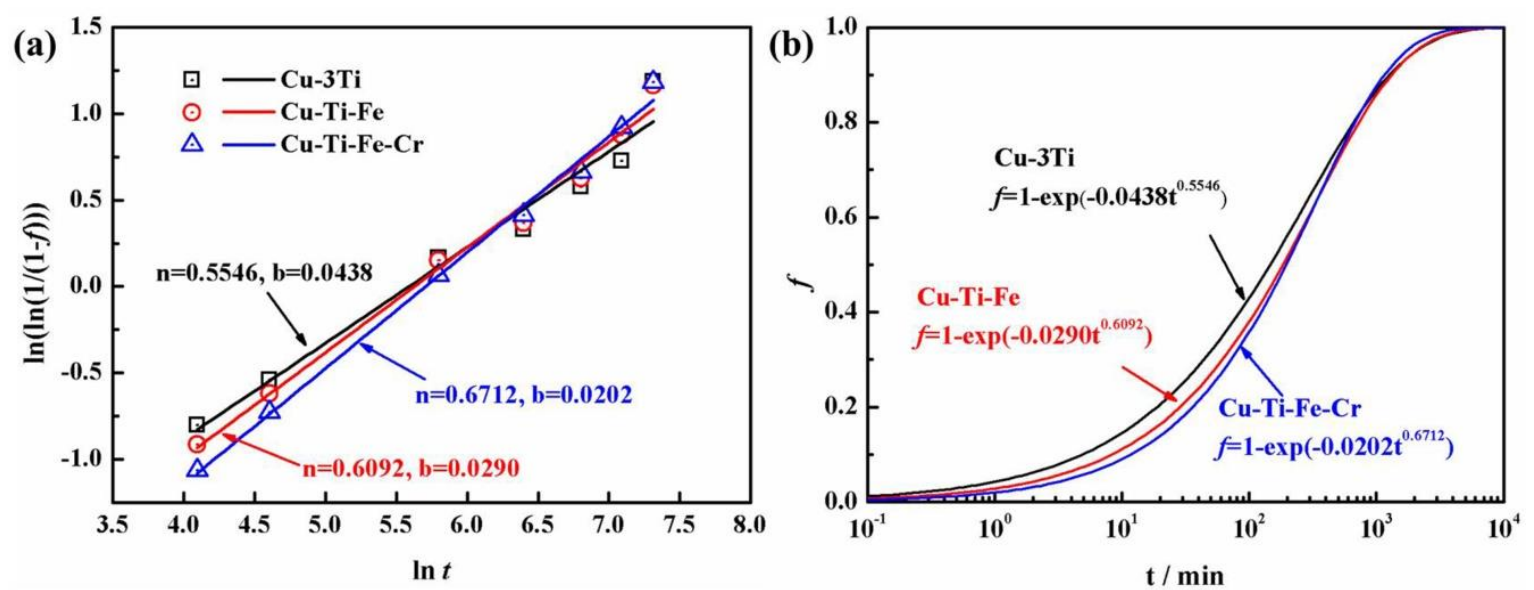

Figure 5. Relation between the volume fraction and the transformation time aging, at $450{ }^{\circ} \mathrm{C}$. (a) Fitting data; (b) kinetic curves of the phase transformation.

\subsection{Electrochemical Measurements}

Electrochemical measurements of all three peak-aged alloy foils were taken in a $3.5 \mathrm{wt} \% \mathrm{NaCl}$ solution, to study the corrosion resistance. The potentiodynamic polarization curves of the three alloys, in the peak-aged condition, are illustrated in Figure 6; it can be seen that all three alloys exhibit the similar polarization behavior. Polarization resistance $R_{p}$ was calculated by the Stern-Geary equation [27]:

$$
R_{P}=\frac{b_{a} \times b_{c}}{2.303\left(b_{a}+b_{c}\right) \times i_{c o r r}}
$$

where $i_{c o r r}$ is the corrosion-current density, and $b_{a}$ and $b_{c}$ are the Tafel constant of the anode and the cathode process, respectively.

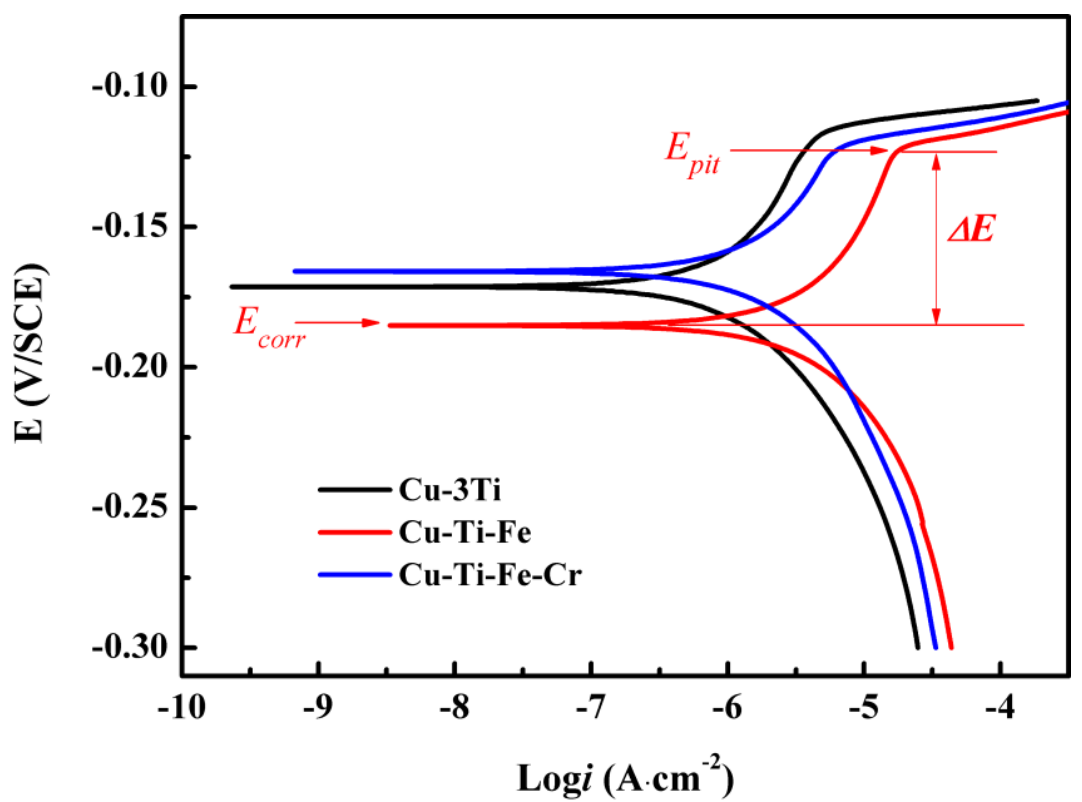

Figure 6. Polarization curves of the three alloys, aging at $450{ }^{\circ} \mathrm{C}$, for the peak-aging time, in $3.5 \mathrm{wt}$. \% $\mathrm{NaCl}$ solution.

Relative polarization parameters have been summarized in Table 4. It shows that the Cu-Ti-Fe alloy had the highest corrosion current density $i_{c o r r}$ and the lowest corrosion potential $E_{\text {corr }}$. The presence of the cathodic second phase $\mathrm{Fe}_{2} \mathrm{Ti}$ accelerated the cathode depolarization process, due to the enlargement of the cathodic area. Therefore, an addition of Fe decreased the $R_{p}$ from $1.392 \mathrm{k} \Omega \cdot \mathrm{cm}^{2}$ of 
$\mathrm{Cu}-3 \mathrm{Ti}$ to $0.809 \mathrm{k} \Omega \cdot \mathrm{cm}^{2}$, indicating a faster corrosion rate. A more uniform potential was obtained on the surface of the $\mathrm{Cu}-\mathrm{Ti}-\mathrm{Fe}-\mathrm{Cr}$ alloy, due to the more uniform distribution and smaller size of the $(\mathrm{FeCr})_{2} \mathrm{Ti}$ phase. In addition, the $\mathrm{Cr}$ element could improve the thermal stability of the $\mathrm{Fe}_{2} \mathrm{Ti}$ phase and suppressed the anodic dissolution, which promoted the intensification of passive films, resulting in an increment of $E_{c o r r}$ from $-185.1 \pm 3.4 \mathrm{mV} / \mathrm{SCE}$, for the Cu-Ti-Fe alloy, to $-165.8 \pm 3.7 \mathrm{mV} / \mathrm{SCE}$, and the remarkable increment of the $R_{p}$ from $0.809 \mathrm{k} \Omega \cdot \mathrm{cm}^{2}$ to $6.538 \mathrm{k} \Omega \cdot \mathrm{cm}^{2}$. It is also worth noting that the passive region $\left(\Delta E=E_{\mathrm{pit}}-E_{\mathrm{corr}}\right)$ of the $\mathrm{Cu}$-Ti-Fe alloy was higher than that of the $\mathrm{Cu}$-3Ti and the $\mathrm{Cu}-\mathrm{Ti}-\mathrm{Fe}-\mathrm{Cr}$ alloys, indicating a better blunt ability. The difference of the passive regions might be attributed to the rapture and recovery of the passive film, on the surface of the Cu-Ti series alloys. It is known that a good corrosion resistance is evaluated by a low value of $i_{c o r r}$ and high values of $E_{c o r r}$ and $R_{p}$. Therefore, on the basis of the relative polarization parameters, the $\mathrm{Cu}-\mathrm{Ti}-\mathrm{Fe}-\mathrm{Cr}$ alloy represented a better corrosion resistance, in $3.5 \mathrm{wt}$. \% NaCl solution.

Table 4. Polarization parameters of the three alloys aging, at $450^{\circ} \mathrm{C}$, for the peak-aging times.

\begin{tabular}{|c|c|c|c|c|c|c|c|}
\hline Alloys & $\begin{array}{c}i_{\text {corr }} \\
\left(\mu \mathrm{A} \cdot \mathrm{cm}^{-2}\right)\end{array}$ & $\begin{array}{c}E_{\text {corr }} \\
(\mathrm{mV} / \mathrm{SCE})\end{array}$ & $\begin{array}{c}E_{p i t} \\
\text { (mV/SCE) }\end{array}$ & $\begin{array}{c}\Delta E \\
\text { (V/SCE) }\end{array}$ & $\begin{array}{c}b_{c} \\
(\mathrm{mV} / \mathrm{dec})\end{array}$ & $\begin{array}{c}b_{a} \\
(\mathrm{mV} / \mathrm{dec})\end{array}$ & $\begin{array}{c}R_{p} \\
\left(\mathrm{k} \Omega \cdot \mathrm{cm}^{2}\right)\end{array}$ \\
\hline Cu-3Ti & $\begin{array}{c}2.887 \pm \\
0.055\end{array}$ & $\begin{array}{c}-171.3 \pm \\
4.2\end{array}$ & $\begin{array}{c}-121.2 \pm \\
2.5\end{array}$ & 50.1 & $111.1 \pm 3.3$ & $10.1 \pm 1.8$ & 1.392 \\
\hline $\mathrm{Cu}-\mathrm{Ti}-\mathrm{Fe}$ & $\begin{array}{c}10.244 \pm \\
0.036\end{array}$ & $\begin{array}{c}-185.1 \pm \\
3.4\end{array}$ & $\begin{array}{c}-122.4 \pm \\
2.9\end{array}$ & 62.7 & $170.2 \pm 5.1$ & $21.5 \pm 2.7$ & 0.809 \\
\hline $\mathrm{Cu}-\mathrm{Ti}-\mathrm{Fe}-\mathrm{Cr}$ & $\begin{array}{c}2.689 \pm \\
0.034\end{array}$ & $\begin{array}{c}-165.8 \pm \\
3.7\end{array}$ & $\begin{array}{c}-115.2 \pm \\
3.1\end{array}$ & 50.6 & $116.7 \pm 3.9$ & $62.0 \pm 2.4$ & 6.538 \\
\hline
\end{tabular}

\section{Conclusions}

In the present work, we examined the mechanical properties, the electrical properties, and the corrosion resistance of the $\mathrm{Cu}-3 \mathrm{Ti}, \mathrm{Cu}-\mathrm{Ti}-\mathrm{Fe}$, and the $\mathrm{Cu}-\mathrm{Ti}-\mathrm{Fe}-\mathrm{Cr}$ alloy foils. The results are summarized as follows. (1) Addition of $\mathrm{Fe}$ and $\mathrm{Cr}$, in the binary $\mathrm{Cu}-3 \mathrm{Ti}$ alloy, had not only increased the aging time, for obtaining peak hardness, from 60 to $100 \mathrm{~min}$, but also increased the peak hardness value from $340.2 \pm 4.0 \mathrm{HV}$ to $357.1 \pm 4.6 \mathrm{HV}$. The UTS and YS values of the peak-aged Cu-Ti-Fe-Cr alloy were significantly higher than those of Cu-3Ti alloy, 13\% and 5.7\%, respectively. (2) All modes of fracture of the alloys were in the mixed mode, which composed of flat facets that resembled cleavage and dimples.(3) The electrical conductivity of the peak-aged Cu-Ti-Fe-Cr alloy was $12.5 \pm 0.1 \%$ IACS, which was 3.3\% higher than that of the $\mathrm{Cu}-\mathrm{Ti}-\mathrm{Fe}$ alloy, due to the fewer Ti atoms in the $\mathrm{Cu}$ matrix. (4) $\mathrm{Cu}$-Ti-Fe-Cr alloy with the lowest $i_{\text {corr }}$, and the highest $E_{c o r r}$ and $R_{p}$, represented the better corrosion resistance, in a 3.5 wt. \% $\mathrm{NaCl}$ solution.

Author Contributions: H.Z., Y.D. and X.D. designed and drafted the manuscript; Y. D. and R.L. contributed to the sample preparation; Y. D. and M.W. performed the statistical analysis; H.Z., Y.D. and X.D. revised the manuscript; H.Z., Y.D. and M.W. provided assistance for data acquisition and data analysis; all authors read and approved the final manuscript.

Funding: This research was funded by the National Natural Science Foundation of China (No.51801186), the Fund of the State Key Solidification Laboratory of Solidification Processing in Northwestern Polytechnical University (No. SKLSP 20814), and the Key Technologies R \& D Program of Sanmenxia City (2016010108).

Conflicts of Interest: The authors declare no conflict of interest.

\section{References}

1. Nagarjuna, S.; Sharma, K.K.; Sudhakar, I.; Sarma, D.S. Age hardening studies in a Cu-4.5Ti-0.5Co alloy. Mater. Sci. Eng. A 2001, 313, 251-260. [CrossRef]

2. Xiao, X.P.; Yi, Z.Y.; Chen, T.T.; Liu, R.Q.; Wang, H. Suppressing spinodal decomposition by adding Co into Cu-Ni-Si alloy. J. Alloys Compd. 2016, 660, 178-183. [CrossRef]

3. Wei, H.; Cui, Y.C.; Cui, H.Q.; Wei, Y.H.; Hou, L.F. Effects of multiple trace alloying elements on the microstructure and properties of Cu-4wt\% Ti alloys. Mater. Sci. Eng. A 2017, 707, 392-398. [CrossRef] 
4. Nagarjuna, S.; Srinivas, M.; Balasubramanian, K.; Sarma, D.S. The alloy content and grain size dependence of flow stress in Cu-Ti alloys. Acta Mater. 1996, 44, 2285-2293. [CrossRef]

5. Li, S.; Li, Z.; Xiao, Z.; Li, S.H.; Shen, L.N.; Dong, Q.Y. Microstructure and property of Cu-2.7Ti$0.15 \mathrm{Mg}-0.1 \mathrm{Ce}-0.1 \mathrm{Zr}$ alloy treated with a combined aging process. Mater. Sci. Eng. A 2016, 650, 345-353.

6. Nagarjuna, S.; Balasubramanian, K.; Sarma, D.S. Effect of prior cold work on mechanical properties, electrical conductivity and microstructure of aged Cu-Ti alloys. J. Mater. Sci. 1999, 34, 2929-2942. [CrossRef]

7. Betra, I.S.; Laik, A.; Kale, G.B.; Dey, G.K.; Kulkarni, U.D. Microstructure and properties of a Cu-Ti-Co alloy. Mater. Sci. Eng. A 2005, 402, 118-125. [CrossRef]

8. Suzuki, S.; Hirabayashi, K.; Shibata, H.; Mimura, K.; Isshiki, M.; Waseda, Y. Electrical and thermal conductivities in quenched and aged high-purity Cu-Ti alloys. Scripta Mater. 2003, 48, 431-435. [CrossRef]

9. Soffa, W.A.; Laughlin, D.E. High-strength age hardening copper-titanium alloys: redivivus. Prog. Mater. Sci. 2004, 49, 347-366. [CrossRef]

10. Nagarjuna, S.; Balasubramanian, K.; Sarma, D.S. Effect of Ti additions on the electrical resistivity of copper. Mater. Sci. Eng. A 1997, 225, 118-124. [CrossRef]

11. Markandeya, R.; Nagarjuna, S.; Sarma, D.S. Effect of prior cold work on age hardening of Cu-3Ti-1Cr alloy. Mater. Charact. 2006, 57, 348-357. [CrossRef]

12. Markandeya, R.; Nagarjuna, S.; Sarma, D.S. Influence of prior cold work on age hardening of Cu-Ti-Zr alloys. Mater. Sci. Tech-lond 2005, 21, 1171-1180. [CrossRef]

13. Liu, J.; Wang, X.H.; Ran, Q.N.; Zhao, G.; Zhu, X.X. Microstructure and properties of Cu-3Ti-1Ni alloy with aging process. T. Nonferr. Metal. Soc. 2016, 26, 3183-3188. [CrossRef]

14. Toyohiko, J.K.; Rimi, N.; Satoshi, S.; Tetsu, O.; Eiji, O. Aging behavior of Cu-Ti-Al alloy observed by transmission electron microscopy. J. Mater. Sci. 2008, 43, 3761-3768.

15. Wang, X.H.; Chen, C.Y.; Guo, T.T.; Zou, J.T.; Yang, X.H. Microstructure and properties of ternary Cu-Ti-Sn alloy. J. Mater. Eng. Perform. 2015, 24, 2738-2743. [CrossRef]

16. Fernee, H.; Nairn, J.; Atrens, A. Precipitation hardening of Cu-Fe-Cr alloys. J. Mater. Sci. 2001, 36, $2711-2719$. [CrossRef]

17. Wei, H.; Wei, Y.H.; Hou, L.F.; Dang, N. Correlation of aging precipitates with the corrosion behavior of Cu-4wt.\% Ti alloys in 3.5wt.\% NaCl solution. Corros. Sci. 2016, 111, 382-390. [CrossRef]

18. Mineau, L.; Hamar-Thibault, S.J.; Allibert, C.H. Precipitation in Cu-rich Cu-Fe-Ti ternary alloys. Phys. Status. Solidi. A 1993, 137, 87-100. [CrossRef]

19. Bo, H.; Wang, J.; Duarte, L.; Leinenbach, C.; Liu, L.B.; Liu, H.S.; Jin, Z.P. Thermodynamic re-assessment of Fe-Ti binary system. T. Nonferr. Metal. Soc. 2012, 22, 2204-2211. [CrossRef]

20. Wang, X.F.; Zhao, J.Z.; He, J. Investigation on the microstructure and mechanical properties of the spray-formed Cu-Cr alloys. Mater. Sci. Eng. A 2007, 460, 69-76. [CrossRef]

21. Atsunori, K.; Takahiro, K.; Mauo, O. Effects of dehydrogenation heat-treatment on electrical-mechanical properties for hydrogenated Cu-3 mass\% Ti alloys. J. Alloys Compd. 2013, 566, 1-4.

22. Satoshi, S.; Mikio, I.; Shigeo, S.; Kazuaki, W.; Takayuki, T. Extraction of precipitates from age-hardenable Cu-Ti alloys. Mater. Charact. 2013, 82, 23-31.

23. Satoshi, S.; Shintaro, A.; Jie, F.; Akihiro, I.; Takayuki, T. Kinetics and equilibrium of age-induced precipitation in Cu-4at.\% Ti binary alloy. Metall. Mater. Trans. A 2017, 48, 1501-1511.

24. Lei, Q.; Li, Z.; Pan, Z.Y.; Wang, M.P.; Xiao, Z.; Chen, C. Dynamics of phase transformation of Cu-Ni-Si alloy with super-high strength and high conductivity during aging. T. Nonferr. Metal. Soc. 2010, 20, 1006-1011. [CrossRef]

25. Avrami, M. Kinetics of phase change I general theory. J. Chem. Phys. 1939, 7, 1103-1112. [CrossRef]

26. Cahn, J.W. Thermodynamic aspects of Cottrell atmospheres. Philos. Mag. 2013, 93, 3741-3746. [CrossRef]

27. Stern, M.; Geary, A.L. Electrochemical polarization I. A Theoretical analysis of the shape of polarization curves. J. Electrochem. Soc. 1957, 104, 56-63. [CrossRef]

(C) 2018 by the authors. Licensee MDPI, Basel, Switzerland. This article is an open access article distributed under the terms and conditions of the Creative Commons Attribution (CC BY) license (http:/ / creativecommons.org/licenses/by/4.0/). 